\title{
Kidney Lymphoma
}

National Cancer Institute

\section{Source}

National Cancer Institute. Kidney Lymphoma. NCI Thesaurus. Code C63532.

A lymphoma that arises from the kidney. There is no evidence of a systemic lymphoproliferative disorder. 